newly hatched larvæ recently studied show that in this species also we have the same characteristics that $I$ have referred to in the case of the Bean. Weevil. The temporary legs are much shorter and stouter, but similarly constructed, the tarsus proper being merely a spatulate pad. The spurs on the prothoracic segment are more elaborate and more conspicuous. They consist of about six strong retrorse spines anteriorly, succeeded by two more prominent plates, also pointing posteriorly and strongly toothed along their exterior border. There are no anal spurs or spines. An interesting fact connected with this larva is that while ordinarily entering the pea direct from the amber-coloured egg, as previously recorded, it sometimes enters the pod in the neighborhood of the egg and then mines along the inside of the pod for some distance, being quite active and moving rapidly and with ease. This doubtless occurs wherever the egg hatches before the peas are sufficiently developed, the larva living as a miner until the pea is nearly full -grown. The entrance of the larva into a pea in such case would seem to be rather by chance than design. As in the case of the Bean Weevil, however, the larva molts and loses its legs and other post-embryonic characters as soon as it has penetrated the pea.

\title{
SOME NOTES ON THE MARGINED SOLDIER-BEETLE (CHAULIOGNATHUS MARGINATUS).
}

\author{
BY C. V. RILEY, WASHINGTON, D. C.
}

Since the larval history of this beetle was published by Walsh in I 868 it has been generally known that the larva is carnivorous, feeding, as Walsh showed, upon the Plum Curculio, and, as I showed, on the Apple Worm among other insects, so that it must be included among our beneficial species. The larva is also one of those which is quite often found during the winter montlus upon the surface of snow. The beetle is one of the most common species during the summer months upon many kinds of flowers, but particularly upon those of Yucca, feeding principally on pollen, but also sipping the slight amount of nectar which is found at the base of the pistil, or the sweetened exudation which is also quite frequent upon the tip of the petiole of the flower after this has dropped. It is quite frequently found in pairs, and there is no difficulty in getting the female to lay her eggs, but so far as I know the eggs have hitherto 
been unknown, and no record of them made. It occurred to me, therefore, that a brief statement might be interesting.

The eggs are laid, not in the ground, but on the surface of the ground, and preferably under some shelter, as a stone or a piece of wood. In the vivarium pieces of crockeryware have been made use of. In nature the shade afforded by the dense, more or less recumbent foliage of Yucca filamentosa doubtless furnishes a desirable situation. The eggs are laid in clusters, some of them as large as an ordinary pea. They are very pale yellowish, almost white, highly polished and faintly rugose. They are nearly globular, or but very slightly ovoid. I have counted over 300 eggs in a single mass, and each egg measures $0.25 \mathrm{~mm}$. in length and 0.27 in diameter. The newly hatched larva is pure white but otherwise has the same form and general appearance as when full grown.

\section{THE SPECIES OF MAMESTRA.}

BY A. R, GROTE, A. M,

By favour of the Secretary of the Smithsonian Institution, I have received a copy of the "Revision of the species of Mamestra by John B. Smith, Professor of Entomology, Rutgers College, Washington, $189 \mathrm{r}$ ". There are one or two points only upon which I desire here to comment. As a whole the determinations agree with my own. The genus Dianthoecia is merged with Mamestra, as I at one time proposed from the variability in the same species of the ovipositor. But, as I pointed out in my last Check List, p. $\mathrm{I}_{3}$, the characters of Dianthoecia, Bdv, are taken from the habit of the larva, the button-like termination of the wing cases in the chrysalis and the extended ovipositor in the moth. The American forms have been only incompletely studied for these characters. The genus is universally adopted in Europe, and our "cabinet opinions" will doubtless be modified when we come to know the preparatory stages of our species.

So far as the Revision is concerned, I may discuss the following synonymical points. And first, on page 218 , my $M$. vittula is very fully described from my type, shown to the author of the Revision by Prof. Snow. Yet, on page 268 , this same species is stated to be "unknown", and is further unfavourably commented on as too near to 4 -lineata, while on page $2 \mathrm{I} 9$ the type is said to be "much more nearly allied to capsularis 